\title{
La retórica rusófoba y anglófoba del régimen franquista en las películas Murió hace quince años, Rapsodia de sangre, y La mujer que vino del mar
}

\author{
Javier Venturi \\ University of Massachusetts-Amherst, United States of America
}

\begin{abstract}
The defeat of Nazi Germany and Fascist Italy in World War II (1939-1945) and the approval of Resolution 39 by the General Assembly on February 9th, 1946, which determined the exclusion of Spain from international organizations established by the United Nations, forced the Francoist regime to modify its fascist agenda and territorial ambitions in Europe, North Africa, and its former colonies in America. Under this scenario, the Francoist regime affirmed that the USSR's political and military intervention was to blame for the Spanish Civil War (1936-1939), and for the socioeconomic crisis that followed. The Spanish sentiment of Russophobia and Anglophobia was politically justified and promoted by the Francoist regime's propaganda since the beginning of the Spanish Civil War, and it proceeded during the Cold War period as well. The virtual isolation of Spain ended with the signature of the Pact of Madrid on September 23rd, 1953. The strategic pact with the United States allowed the Francoist regime to: consolidate a new military alliance; legitimize its power over victors and vanquished of the Spanish Civil War; revive the economy after the failure of autarchic policies; and refocus its gaze on its foreign enemies. The following movies: "He Died Fifteen Years Ago" (Dir. Rafael Gil, 1954); "The Woman Who Came from the Sea" (Dir. Francesco de Robertis, 1957); and "Blood Rhapsody" (Dir. Antonio Isasi-Isasmendi, 1957) embrace the forceful Francoist regime's cinematic rhetoric that aims to delegitimize its historical political nemeses: USSR and United Kingdom, Communism and the unresolved Gibraltar issue, respectively.
\end{abstract}

Keywords: Historical Memory, Francoist Regime, Cold War Cinema, Film Noir, Russophobia and Anglophobia

\section{Introduction}

A raíz de la derrota de Alemania, Italia, y Japón en la Segunda Guerra Mundial, la Nueva España de Franco se vio obligada a renunciar al sueño de expansión del fascismo a escala global, y subsiguientemente, debió distanciarse de los originales propósitos del nacionalsindicalismo radical -26 puntos de Falange Española Tradicionalista y de las JONS - cuando la comunidad internacional, hostil hacia los reductos del fascismo en la Europa de la postguerra, condenó España a un severo aislamiento internacional con la entrada en vigor de la Resolución 39(I) de la Asamblea General de la ONU del 9 de febrero de 1946. En San Francisco, Potsdam y Londres, los pueblos de las Naciones Unidas condenaron el régimen de Franco y decidieron que, mientras continuara ese régimen, España no ha de ser admitida en el seno de las Naciones Unidas.
El veredicto final sobre la "cuestión española" fue emitido y ratificado por la Asamblea General con la siguiente justificación:

El Subcomité del Consejo de Seguridad encargado de la investigación determinó por unanimidad: (a) En su origen, naturaleza, estructura y conducta general, el régimen de Franco es un régimen fascista y se estableció en gran parte como resultado de la ayuda recibida por la Alemania nazi de Hitler, y la Italia fascista de Mussolini. (GA Res. 39 (I): 57-58)

El apoyo logístico y militar brindado por el régimen fascista español a las potencias del Eje durante la Segunda Guerra Mundial, no fue indultado ni por la ONU ni por los Aliados. Por consiguiente, las secuelas de las sanciones diplomáticas y económicas, impuestas por la comunidad internacional, incrementaron el riesgo de inestabilidad política y agitación social en la renovada España de Franco a partir de 1946. Ante la creciente posibilidad de una acción intervencionista de potencias extranjeras como los Estados Unidos, Francia, Reino Unido, y la URSS, el régimen franquista optó por la instauración de la medida económica de liberalización parcial del comercio como solución preventiva contra la instabilidad político-social y, de esta forma, evitar un nuevo conflicto fratricida. El éxito relativo de la nueva política económica permitió al régimen franquista de proseguir con la fase de homogeneización y apaciguamiento forzado de una sociedad española, aparentemente desfasticizada, y confirmó a su vez, la primera victoria política de los emergentes grupos de poder tecnócratas del Opus Dei. La liberación parcial del comercio evidenció también el fracaso de la política autárquica sostenida desde 1939 por Falange Española Tradicionalista y de las JONS, y paralelamente, puso fin a la distribución de las cartillas de racionamiento a partir de 1952. Sin embargo, los rezagos socioeconómicos de la Guerra Civil como el hambre y la miseria, y el brote de enfermedades como la tuberculosis y la poliomielitis, permanecieron irremediablemente inmutados en la sociedad española hasta mediados de la década de los 60 .

La nueva faceta de una España nacionalcatólica, defasticizada en apariencia, y dedicada en promover un aperturismo económico bien controlado, pudo implementarse con mayor facilidad, gracias a las secuelas políticas y económicas derivadas por el nuevo posicionamiento del Estado español en el panorama geopolítico mundial surgido tras la Segunda Guerra Mundial. El cambio cosmético del régimen franquista facilitó el establecimiento de las alianzas estratégicas con el Estado de la Ciudad del Vaticano y con los Estados Unidos. Ambas alianzas fueron ratificadas a través de la firma del Concordato con la Santa Sede, firmado en la Ciudad del Vaticano el 27 de agosto de 1953, y los Pactos 
de Madrid, firmados el 23 de septiembre de 1953, respectivamente. Los acuerdos ejecutivos bilaterales autorizaron la instalación en España de cuatro bases estadounidenses a cambio de ayuda económica y asistencia militar. En particular, se debe reconocer que los acuerdos ejecutivos bilaterales estipulados por España y los Estados Unidos, confirmaron el fin del aislamiento internacional del régimen franquista y, paralelamente, solidificaron la presencia del General Francisco Franco en el poder como líder supremo, y bastión de la resistencia anticomunista en Europa occidental. El aperturismo económico y el acuerdo de cooperación bilateral establecido con los Estados Unidos —el nuevo aliado ideológico, militar, y económico - otorgó una bocanada de oxígeno a la estancada economía española de los años 50. Sin embargo, esta alianza estratégica estableció también el reconocimiento de la soberanía, y la no interferencia en los asuntos internos del Estado español, y sobre todo otorgó al régimen franquista un estatus especial de inmunidad e impunidad, el cual le permitió encubrir la brutal represión política, y las graves violaciones de los derechos humanos perpetradas a partir de la Guerra Civil.

Cabe señalar que, la agenda eugenésica implementada por el régimen franquista durante la fase de homogeneización de la sociedad española, fue a su vez transplantada en Hispanoamérica y, subsiguientemente adoptada por las dictaduras militares de derecha a partir de la Guerra Fría. Por consiguiente, las voces de protesta provenientes de algunos países miembros de la comunidad internacional como el Reino Unido, y especialmente aquellas provenientes de los países miembros del Bloque del Este, fueron muy críticas respecto a la legalidad y legitimidad democrática del régimen franquista, el cual además de acoger y proteger criminales de guerra nazis - la red de colaboración secreta ODESSA - fue declarado responsable de grandes violaciones de los derechos humanos. La lucha ideológica entablada entre los países de postura comunista y postura anticomunista, se intensificó a través de medios de comunicación escritos, sonoros, y sobre todo a través de medios de comunicación y persuasión audiovisuales como el cine de propaganda. En esta circunstancia, el cine de propaganda soviético, ya emblemático antagonista del nazi-fascismo durante la Guerra Civil española y la Segunda Guerra Mundial —Gran Guerra Patria para la URSS - proseguirá con mayor ahínco la lucha ideológica contra los reductos del fascismo en Europa y a escala global durante las décadas de los 50 y 60 . La victoria del Ejército Rojo -Ejército Soviético a partir de 1946 - sobre el nazi-fascismo es exaltada a través de las siguientes películas bélicas soviéticas: La caída de Berlin (Dir. Mikheil Chiaureli, 1950); Cuando pasan las cigüeñas (Dir. Mikhail Kalatozov, 1957); La balada del soldado (Dir. Grigori Chukhrai, 1959); y por el documental El fascismo ordinario (Dir. Mikhail Romm, 1965).

Es importante notar que, las películas de propaganda soviética producidas por DEFA (Deutsche
Film-Aktiengesellschaft), Tengo sed (Dir. Karl Paryla, 1956) y Cinco casquillos de bala (Dir. Frank Beber, 1960), ambas producidas en la República Democrática Alemana bajo la sombra del Telón de Acero, y el documental francés que burló astutamente la censura franquista, Morir en Madrid (Dir. Frédéric Rossif, 1963), se distinguen por sus discursos narrativos fílmicos de postura netamente antifascista, los cuales solidarizan abiertamente con las voces disidentes y las víctimas del genocidio franquista. Por su lado, el régimen franquista desacreditó constantemente la URSS y sus países satélites a través de un cine de propaganda, de postura netamente anticomunista, y extremadamente rusófobo -Rusia se convirtió en el chivo expiatorio de los males de España a raíz de su intervención en la Guerra Civil española- y por ello, es importante evidenciar la existencia de dos etapas significativas de la cinematografía franquista, ambas producidas en el periodo inicial de la Guerra Fría: La etapa del “olvido y la autarquía (1943-1950)," y la etapa del "cine político anticomunista, de 'Arcadia asediada por el enemigo exterior (1951-1957)'” (Sánchez Barba 2007, 56). Consecuentemente, la lucha ideológica entablada por la España nacionalcatólica contra el comunismo internacional proseguirá durante la década de los 50, y ésta será propagada por las voces partidarias a través un cine español que entretiene y, a su vez, proselitiza la mirada espectatorial en el plano ideológico, psicológico, socio-cultural, y religioso.

En lo que concierne al papel desempeñado por las voces partidarias en el cine español de los años 50 , se puede constatar que estas voces fueron omnipresentes y dominantes del discurso hegemónico franquista, el cual fue difundido por medio de películas que exaltan la identidad nacional a través de la virtuosidad de la mujer española, y el modelo patriarcal de masculinidad. El régimen franquista utilizó la popularidad del cine por su incidencia económica e influencia social, y por ello, el discurso hegemónico difundido a través del cine representó la respuesta mediática, e ideológicamente contrapuesta, a la postura antifascista del cine de propaganda soviético. Si bien los objetivos y las temáticas del cine de propaganda soviético, contrastan ideológicamente y estéticamente con los del cine de postura nacionalcatólica del régimen franquista, es importante tener en claro que, ambos regímenes dictatoriales, utilizaron las imágenes cinematográficas como eficaz instrumento audiovisual de persuasión emocional, adoctrinamiento ideológico, y control social. Por lo tanto, para vencer la guerra de propaganda en el ámbito de la política interior e internacional, el régimen franquista se vio obligado a controlar muy de cerca la producción cinematográfica a larga escala de películas comprometidas con la difusión y defensa de la ideología nacionalcatólica. Los discursos narrativos fílmicos, elaborados por la máquina de propaganda cinematográfica franquista, funcionaron como antídoto audiovisual contra todas las voces disidentes que cuestionaban los dictados ideológicos y políticos del régimen de Franco, sea en España como en el extranjero. 


\section{La retórica rusófoba franquista en las películas Murió hace quince años y Rapsodia de sangre}

Las alianzas estratégicas establecidas por el Estado español con los países del Bloque Occidental o Bloque Capitalista y con la Ciudad del Estado Vaticano, no solamente legitimaron el régimen autoritario sino también reconocieron el firme valor de España como bastión anticomunista en Europa. A raíz de la Guerra Fría, la propagación de la retórica anticomunista del régimen franquista adquirió mayor importancia, y esta tendencia política se vio reflejada firmemente en las producciones cinematográficas de los años 50. Por consiguiente, la representación cinematográfica de la URSS y de sus países satélites - la amenaza roja- es propuesta a la mirada espectatorial como un cáncer que asola el rígido orden social respaldado por el Estado español y la Iglesia católica, y defendido a su vez por el garante de la sagrada unidad territorial de España, Francisco Franco. Sin embargo, la brutal represión y persecución política de los disidentes antifranquistas - ejecutada por manos de agencias represivas como la Brigada de Investigación Social (BSI) y la Guardia Civilfue cuidadosamente encubierta por los organismos de censura franquista. La ausencia de un asequible repertorio literario, fotográfico, y cinematográfico que pudiera testimoniar la auténtica realidad social y no aquella construida a través del filtro de la censura y la brutal represión, demuestra la voluntad política de un régimen dictatorial que no concedió ningún espacio propio a las voces alternativas e ideológicamente contrapuestas al nacionalcatolicismo y, por lo tanto, las voces disidentes antifranquistas fueron en gran parte represaliadas desde el plano ideológico, moral, religioso, social, histórico, y cultural. Como consecuencia de ello, las huellas de la brutal represión política fueron sistemáticamente borradas, y la omisión de las secuelas visibles de esta "violencia silenciosa" formaron parte de la cotidianidad de una sociedad española que fue físicamente e psicológicamente subyugada a través de la ideología del miedo. El supuesto peligro inminente de la amenaza roja, fue instrumentalizado por la régimen franquista como arma de dominación política y control social, y esta obsesión contribuyó a la aceptación social voluntaria o forzada- de la brutal represión política, la cual se consolidó con la puesta en practica de la omertà —código de silencio practicado por la mafia italiana - ante el justificado miedo a las represalias. El ocultamiento intencional de los crímenes contra la humanidad obedece también a la tendencia política disgregadora del régimen franquista, la cual condenó la memoria histórica de los vencidos en el olvido con la puesta en práctica de la damnatio memoriae, y esta política disgregadora se materializó también en el ámbito de las producciones cinematográficas españolas de la década de los 50. Por ende, las voces disidentes consideradas como antipatrióticas y antifranquistas, recibirán el mismo tratamiento a nivel cinematográfico, de ahí que las escenas de persecución, allanamiento de morada, la detención y posterior desaparición de los enemigos y traidores de España, fueron justificadas por la propaganda cinematográfica franquista a través de películas que exaltan la efectividad de la justicia ordinaria y la infalibilidad de la justicia divina, Estado español e Iglesia católica, respectivamente.

La matriz ideológica y espiritual del nacionalcatolicismo español se personifica en la relación de simbiosis entre la justicia ordinaria y la justicia divina, y ambas justicias made in Spain fueron promovidas a través de la popularidad de películas del cine negro español como: Brigada criminal (Dir. Ignacio F. Iquino, 1950); Apartado de correos 1001 (Dir. Julio Salvador, 1950); Mañana cuando amanezca (Dir. Javier Setó, 1955); y La ciudad perdida (Dir. Margarita Alexandre y Rafael Torrecilla, 1955), y a través de películas del cine religioso español como: Agustina de Aragón (Dir. Juan de Orduña, 1950); La señora de Fátima (Dir. Rafael Gil, 1951); Alba de América (Dir. Juan de Orduña, 1951); y La leona de Castilla (Dir. Juan de Orduña, 1951). Es importante recalcar que, la agenda política interior y exterior del régimen franquista, coincidió en muchos aspectos con la agresiva política intervencionista y anticomunista de los Estados Unidos, la cual se manifestó a través de películas del cine negro estadounidense como: Culpable de traición (Dir. Felix E. Feist, 1950); El gran Jim McLain (Dir. Edward Ludwig, 1952); y Manos peligrosas (Dir. Samuel Fuller, 1953). Por ende, los ecos de la inquisición política estadounidense, cuya cruzada anticomunista justificó la exacerbada persecución de personas sospechadas de ser comunistas, y sobre todo de aquellas presentes en sectores de la Administración Pública estadounidense, Radio, Televisión, Broadway, y Hollywood durante el periodo macartista de los años 40 y 50, resonarán también en la retórica rusófoba propagada por las siguientes películas españolas de postura netamente anticomunista: Murió hace quince años (Dir. Rafael Gil, 1954) y Rapsodia de sangre (Dir. Antonio Isasi-Isasmendi, 1957).

Murió hace quince años es una película dramática de matices falangistas, protagonizada por Rafael Rivelles y Francisco "Paco" Rabal, y fue estrenada en España el 4 de octubre de 1954. El guión fue escrito por Vicente Escrivá, y la respectiva adaptación cinematográfica se basa en la obra de teatro homónima Murió hace quince años de José Antonio Giménez-Arnáu, la cual fue laureada con el Premio Lope de Vega en 1952, y con el Premio Nacional de Teatro en 1953. La difusión e instrumentalización con fines propagandísticos de la película Murió hace quince años, refleja de manera obvia el nuevo posicionamiento geopolítico del régimen franquista, de postura netamente anticomunista, la cual se correlaciona con las problemáticas sociales y políticas del periodo de la Guerra Fría, y entre ellas destacan la cuestión irresuelta de la repatriación de los niños de Rusia, y el subsiguiente riesgo de infiltración de espías, activistas, saboteadores, y agitadores comunistas en el territorio español. El período comprendido entre 
1953 y 1954 se caracterizó por algunos sucesos históricos que comprometieron seriamente el equilibrio de poder establecido a partir del comienzo de la Guerra Fría. El ascenso al poder de Nikita Kruschev el primer secretario del Partido Comunista de la URSS del periodo post-Stalin- intensificó el riesgo de una inminente guerra termonuclear entre los los Estados Unidos y la URSS, el cual hizo que las agujas del Reloj del Juicio Final o Apocalipsis marcaran por primera vez los fatídicos dos minutos para medianoche, y el riesgo de expansión del comunismo en Hispanoamérica, el cual fue alentado por la lucha armada emprendida por el movimiento revolucionario cubano de Fidel Castro, justificaron más que nunca la obsesión militarista del régimen franquista de poner fin a la amenaza roja.

Por ende, la campaña de propaganda anticomunista del régimen franquista se expresará cinematográficamente por medio de una retórica rusófoba de fuertes tintes falangistas, la cual se materializa a partir de las primeras secuencias de la película Murió hace quince años. El emblemático titulo de la película se yuxtapone a la imagen del puerto de Bilbao, a la cual subsigue el embarque de los niños republicanos o los niños de Rusia, quienes a su vez son conducidos y celosamente vigilados por soldados republicanos y marineros soviéticos, ambos fácilmente reconocibles porque llevan uniformes de la Revolución bolchevique. La revisitación y manipulación del pasado sirve como pretexto para deslegitimar una vez mas la memoria histórica de los vencidos, y paralelamente denunciar la política intervencionista y militarista de la URSS a partir de la Guerra Civil española. El viaje retrospectivo hacia el espacio temporal de 1937 expone la cuestión irresuelta de los cinco mil niños españoles que, según la historia oficial del régimen franquista -memoria histórica de los vencedores- no fueron evacuados sino llevados contra su voluntad a la URSS. La reconstrucción histórica de la evacuación de los niños de Rusia es utilizada para introducir las vicisitudes de los dos personajes principales de esta película, quienes a su vez representan las dos Españas fragmentadas por la intervención comunista: el Coronel de la policía secreta Diego Acuña, y su hijo Diego, quien fue llevado contra su voluntad a Rusia a la edad de 10 años, y posteriormente regresará a España a la edad de 25 años.

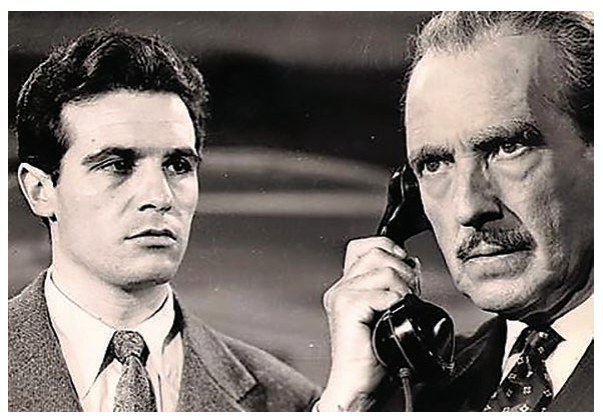

Image 1 - Murió hace quince años (1954)
El regreso de Diego Acuña a España como experto agitador político comunista, y responsable de la muerte de un miembro de las fuerzas del orden durante su participación en la huelga general y las marchas de los trabajadores italianos en Turín, expone el riesgo que podría causar la repatriación incontrolada de los niños de Rusia, y especialmente cuando muchos de los niños españoles han sido expuestos precedentemente a la manipulación psicológica e ideológica de la NKVD (KGB). El proceso de adoctrinamiento ideológico o rusificación de Diego es ilustrado por la propaganda cinematográfica franquista a través de la secuencia en la cual los dos educadores soviéticos enseñan a los jóvenes del Konsomol los siguientes edictos comunistas:

Profesor: La moral está subordinada a los intereses de la lucha de clases. Todo lo que sirve para destruir la sociedad burguesa es bueno; y es malo todo que se opone a la dictadura del proletariado.

Profesora: Ellos mismos lo han dicho: si un estado declara la guerra a otro estado, los hombres pueden matarse, y hasta les premian por hacerlo. La guerra convierte el asesinato en deber, nosotros estamos en guerra permanente con los estados burgueses. Su aniquilamiento es, por tanto, un deber que nadie puede eludir.

Voz en off: La Patria es una palabra hueca para dividir a los hombres; la Familia y la Religión, dos sentimientos enfermizos que adormecen la voluntad del individuo. Hay que desarraigarlos sin piedad.

Voz en off: Todas las revoluciones han fracasado por la blandura de sus jefes; por eso el sentimiento y las lágrimas son basura para nosotros.

Diego: No soy uno más, soy un soldado del pueblo. Mi deber está por encima de mis camaradas, de mis padres, y de mi propia vida; no dejaré pasar un sólo día sin haber hecho algo por la Revolución. El Partido es el arma que ha de impulsar la Revolución. Cuanto se haga, o se piense, no tendrá valor si no sirve para nuestros fines; cada vacilación, cada torpeza que retarda nuestra marcha son crimenes y deben castigarse como tales. Nosotros somos la vanguardia del gran ejército proletario del mundo.

La retórica rusófoba hace hincapié en el específico incidente de la huelga general y las marchas de los obreros en Turín, el cual es utilizado como un ejemplo indiscutible de las secuelas de la infiltración y adoctrinamiento comunista en Italia, y de esta manera, la exacerbada vigilancia y protección de la sociedad española es justificada a nivel cinematográfico por el régimen franquista. Por ende, en la película Murió hace quince años, la amenaza roja es considerada una amenaza para los intereses nacionales, y por ello, la retórica rusófoba se enfocará principalmente en la lucha fratricida de las dos Españas. La relación dicotómica se materializa inicialmente a través del conflicto ideológico existente entre los miembros supervivientes de la familia Acuña, padre e hijo, lealtad vs traición, respectivamente. En lo que concierne a la difusión del mensaje de reconciliación nacional, la propaganda del régimen franquista sostiene que debe ser realizada a través del arrepentimiento y del perdón 
difícil, y esta voz reconciliadora puede ser identificada en Mónica, la prima y amiga de infancia de Diego. El personaje femenino de Mónica representa a su vez el ángel del hogar, un modelo de mujer impuesto por el nacionalcatolicismo, y difundido prolíficamente por el cine español de la década de los 50. De ahí que a través de la intervención o intercesión de Mónica, la lealtad patriótica hacia España y la religión católica, ambas esencias de la españolidad, podrán hacer brecha en el corazón rusificado de Diego. La mimesis cinematográfica del final feliz, presente en las películas de Hollywood, se manifestará en la prueba de lealtad obtenida por Diego a través del arrepentimiento —el perdón difícil lo obtendrá a través de su padre, el Coronel Diego Acuña-y este acto purificador y redentor del hijo pródigo español que regresó de Rusia lo demostrará en la secuencia final con la muerte de Germán Goeritz, un comisario comunista encargado de asesinar el Coronel Acuña. Sin embargo, en la obra teatral Diego muere, y este final alternado confirma la tendencia del cine español de postura anticomunista, en el cual el héroe "comunista" que se arrepiente es acogido como el hijo pródigo en la España nacionalcatólica.

Si bien se puede constatar que la retórica rusófoba presente en la película Murió hace quince años se enfoca principalmente en cuestiones asociadas a la seguridad interna del Estado español, en la película Rapsodia de sangre (Dir. Antonio IsasiIsasmendi, 1957), el enfoque de la retórica rusófoba del régimen franquista se dirigirá principalmente hacia las cuestiones asociadas a la brutal represión ejercida por la URSS en sus países satélites del Bloque del Este. La película Rapsodia de sangre se caracteriza principalmente por el enfoque dedicado a la insurrección popular y a la subsecuente invasión soviética de Hungría en 1956. El anhelo del espíritu de libertad contrapuesto al espíritu deshumanizado y descristianizado que justifica la represión de la libertad y la inexistencia de Dios, es representado a través de la relación dicotómica existente entre el pianista Andras Pulac y el Comandante Igor Solov, patriota húngaro vs traidor comunista, respectivamente. La propaganda cinematográfica franquista exacerba la visión maniquea que divide de manera simplista el conflicto ideológico existente entre los países del Bloque Occidental y del Bloque del Este. Ambos bloques son representados como la lucha eterna entre el bien y el mal, respectivamente. La retórica rusófoba presente en esta película solidariza desde un plano sociopolítico y sociocultural con una sociedad húngara "comunista" pero de profundas raíces católicas. El nexo ideológico que une los disidentes húngaros con los países anticomunistas del Bloque Occidental, se realiza a través de la presencia de dos periodistas italianos de -Attualitá Italiana- Elio y Paolo. Ambos personajes representan el cordón umbilical que une la marginada y esclavizada Hungría con los países de la Europa libre, católica, y democrática. El espíritu de solidaridad del Bloque Occidental dirigido hacia el pueblo húngaro que lucha contra el invasor y opresor soviético, puede resumirse con la intervención de Paolo en defensa de Maria Kondor, la hija de Janos
Kondor, un periodista e idealista comunista. El odio revanchista de los anticomunistas húngaros se dirige hacia Maria, y ella es salvada por la rápida intervención del periodista italiano, quien sosteniendo la cámara cinematográfica dice contemporáneamente:

Paolo: ¡Vamos! ¿qué esperáis? adelante pegarle una buena paliza a la muchacha. Yo me encargaré de que esta escena tan edificante llegue a todos los rincones del mundo. Si queréis acabar con los rusos y los traidores, no toméis venganza ni en sus hijos ni en sus mujeres. En estos momentos sois la esperanza de Occidente.

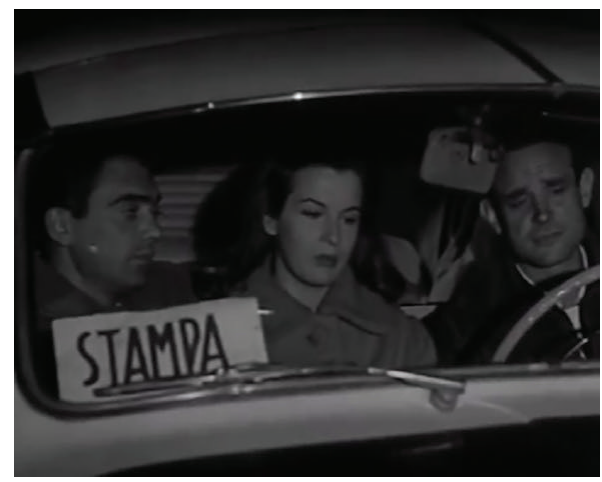

Image 2 - Rapsodia de sangre (1957)

La retórica rusófoba enfatiza a su vez la resistencia ideológica y cultural hacia el comunismo soviético por medio de los mensajeros de la democracia, Paolo y Elio, y a través del pianista de tintes románticos, Andras Pulac. A raíz de la invasión soviética de Hungria en 1956, el joven pianista se niega a dar un concierto frente al líder soviético de Hungría por lo que sufre una gran represión por parte de las autoridades húngaras y soviéticas. Los ecos de las protestas de Posnán de 1956 resuenan en Budapest, y se materializan a través de las melodías de La Polonesa de Frédéric Chopin. Para Andras, tocar en el piano La Polonesa representa el himno dedicado a la anhelada libertad de todas las voces represaliadas por el intervencionismo soviético. La presencia de los personajes de Elio y Paolo, cumplen la función testimonial de los dos testigos oculares del Bloque de Occidente, quienes preservarán a través de un extenso archivo cinematográfico, el aplastamiento de la Revolución húngara de 1956. Sin embargo, en la película Rapsodia de sangre, ante la imposibilidad logística de rodar las escenas asociadas a la represión soviética en Budapest, estas fueron reemplazadas por escenas filmadas en Gerona, Barcelona y Bilbao, a las cuales se yuxtaponen las imágenes de archivo cinematográfico que muestran los enfrentamientos reales sostenidos en las calles de Budapest. La propaganda cinematográfica franquista utiliza la técnica del montaje para evidenciar las atroces secuelas del intervencionismo soviético en Hungría, y de esta manera, la mirada espectatorial es obligada a aceptar la retórica rusófoba y anticomunista del régimen 
franquista. La secuencia final muestra la exitosa fuga en tren de Andras y Maria, la cual representa la continuación del acto de resistir y sobrevivir en el exilio ante la imposibilidad de poder regresar a una Hungría ocupada por las tropas soviéticas.

\section{La retórica anglófoba franquista en la película La mujer que vino del mar}

La película La mujer que vino del mar (Dir. Francesco de Robertis, 1957) conocida también con el título italiano La donna che venne del mare, y con el titulo francés L'aventurière de Gibraltar, es una coproducción italo-francesa filmada en la ciudad española de Algeciras, un enclave geográfico estratégico que se halla en el estrecho de Gibraltar. La voz en off presente en las primeras escenas de la película invita a la mirada espectatorial al viaje retrospectivo hacia el año de 1940, en plena Segunda Guerra Mundial y post-Guerra Civil española. La mujer que vino del mar es una película de espías, y como tal, la ciudad de Algeciras es descrita como un espacio dominado por la presencia de una amplia red de agentes o espías, a los cuales se añaden las incursiones nocturnas de buzos británicos e italianos empeñados en actos de sabotaje mutuo. La película La mujer que vino del mar establece algunos paralelos cinematográficos con la película de espías estadounidense Casablanca (Dir. Michael Curtis, 1942). La ciudad de Algeciras es un espacio urbano en el cual se respeta la neutralidad declarada por el Estado español, de la misma manera que en la ciudad de Casablanca, la neutralidad declarada por la Francia de Vichy, es respetada y a su vez vigilada celosamente por el Prefecto de Policía, el Capitán Louis Renault. Sin embargo, a pesar de la presencia de una amplia red de espías, la representación cinematográfica del Comisario de Policía de Algeciras, confirma a la mirada espectatorial que la ciudad española es bien controlada, y vigilada celosamente por el Estado español.

La representación cinematográfica de las autoridades españolas y de los espacios domésticos y públicos que ocupan los ciudadanos españoles, han sido cuidadosamente despojados de todos los referentes visibles asociados a la España falangista de 1940. Si bien la película fue estrenada en 1957, es obvio que el régimen franquista evitó crear cualquier tipo de incidente diplomático con el Reino Unido, especialmente cuando el régimen franquista fue duramente sancionado por las Naciones Unidas en 1946. La retórica antiamericana expuesta inicialmente por la propaganda franquista en la película Raza (Dir. José Luis Sáenz de Heredia, 1941), la cual fue posteriormente mitigada en las películas Espíritu de una raza (Dir. José Luis Sáenz de Heredia, 1950) y Bienvenido Mr. Marshall! (Dir. Luis García Berlanga, 1953), se transformará posteriormente en retórica anglófoba a raíz de la cuestión irresuelta de la soberanía de Gibraltar. Obviamente, en La mujer que vino del mar, la retórica anglófoba no será difundida explícitamente por los españoles sino por los italianos. Ambos personajes anglófobos están representados por la espía Danae Niebel (Sandra Milo) y por el Cónsul Bordogin (Vittorio de Sica). Las señas de identidad española o españolidad, son difundidas ampliamente a través de secuencias cinematográficas asociadas al baile flamenco, el idioma castellano, y la corrida de toros. La retórica anglófoba es delegada a las voces de los espías, marineros, y submarinistas italianos, quienes a su vez representan las voces de los vencidos de la Segunda Guerra Mundial. La victoria parcial y el éxito obtenido por los espías y buzos italianos en Algeciras asumen la semblanza de un revanchismo a posteriori de matices fuertemente anglófobos. La solidaridad del régimen franquista, la cual es dirigida hacia los ex-aliados ideológicos de la Guerra Civil Española y de la Segunda Guerra Mundial --¡Dios extramaldiga los ingleses! sostenía durante la Segunda Guerra Mundial el periodista radiofónico italiano Mario Appelius-- se materializa a través de la autorización gubernamental para rodar la película en Algeciras. Por último, la retórica anglófoba franquista puede identificarse a través de un guiño cinematográfico e implícitamente ideológico. Se puede concluir que la victoria parcial de los ex-aliados italianos sobre los ingleses, es compartida de manera implícita por la postura anglófoba del régimen franquista, la cual se manifiesta en la película a través del comportamiento indiferente que el Comisario de Policía mantiene con los representantes de la Seguridad Británica. El guiño político o desafío ideológico --a posteriori a las sanciones de 1946-- del régimen franquista puede ser identificado en la oficina del Comisario de Policía de Algeciras. El Escudo de España colgado en la pared es el único referente histórico asociado al pasado falangista. Si bien la secuencia es de breve duración, se puede identificar el lema Una, Grande, Libre, y el yugo y las flechas de Falange Española.

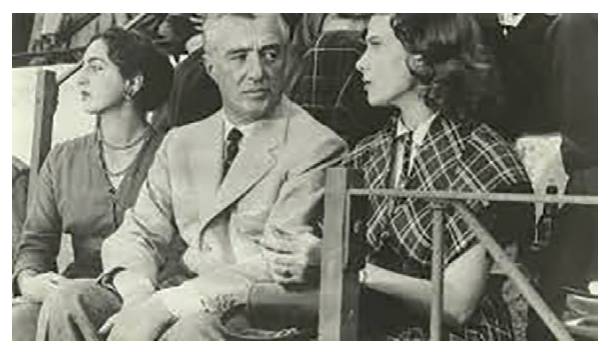

Image 3 - La mujer que vino del mar (1957)

\section{Conclusión}

Es interesante notar que el régimen franquista no tuvo ninguna dificultad en promover a nivel internacional la creación artificial de una España democrática, y comprometida en exponer los crímenes cometidos por naciones de ideologías políticas contrapuestas al nacionalcatolicismo, y paralelamente encubrir las secuelas de la brutal persecución política de los disidentes antifranquistas gracias a las alianzas estratégicas establecidas con los Estados Unidos y el Estado de la Ciudad del Vaticano. Es obvio que la 
difusión cinematográfica de la retórica rusófoba, y en menor grado, la retórica anglófoba, responde a la visión ideológica y militarista de acabar con la amenaza roja, las cuales a su vez han sido instrumentalizadas por el régimen franquista como instrumento hegemónico de penetración y expansión económica a nivel global. Sin embargo, se puede afirmar que las cuestiones asociadas a la recuperación de la memoria histórica de los vencidos, los crímenes contra la humanidad cometidos durante la brutal represión franquista, la soberanía de Gibraltar, y la relación dicotómica de sociedades globales divididas entre rusofobia y rusofilia, deben considerarse como cuestiones aún irresueltas desde el siglo XX.

\section{Websites}

ElPaís 2012, El Gobierno darámas dinero paraabrirfosas del franquismo que los socialistas, at https://politica.elpais. com/politica/2012/04/07/actualidad/1333835306_399718. html, accessed on 14 March 2018.

General Assembly of the United Nations, 39(I). Relations of Members of the United Nations with Spain, at http://www. un.org/en/ga/search/view_doc.asp?symbol=A/RES/39(I), accessed on 7 December 2018.

\section{Filmography}

La mujer que vino del mar. (1957)., Directed by Francesco de Robertis., Italy/Spain.

Murió hace quince años. (1954)., Directed by Rafael Gil., Spain: Video Mercury Films. VHS.

Rapsodia de sangre. (1957)., Directed by Antonio IsasiIsasmendi., Spain.

\section{Bibliography}

Sánchez Barba, Francesc. (2007). Brumas del franquismo: El auge del cine negro español (19501965). Barcelona: Publicacions i Edicions Universitat de Barcelona. 